Title:

Author(s):

Submitted to:
Raymond Dixon, MST-6 Timothy Darling, MST-10 Albert Migliori, MST-10

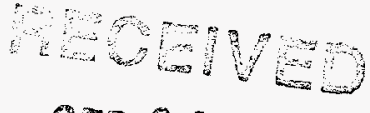

sap 0909

OSTI

DOE Office of Scientific and Technical Information (OSTI)
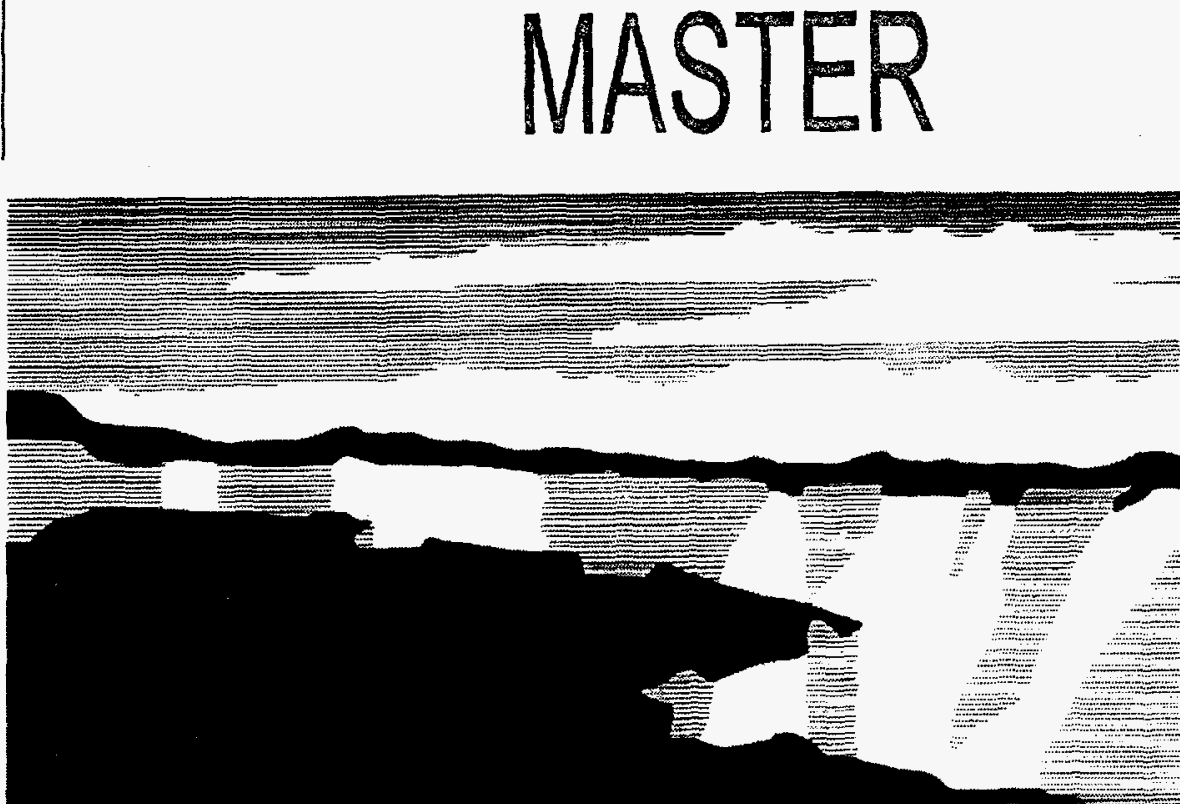

NATIONAL LABORATORY

Los Alamos National Laboratory, an affirmative actionequal opportunity employer, is operated by the University of Calliomia for the U.S. Department of Energy under contract W-7405-ENG-36. By acceptance of this article, the publisher recognizes that the U.S. Government retains a nonexclustive, royaltyfree license to publish or reproduce the published form of this contribution, or to allow others to do so, tor U.S. Govermment purposes. The Los Alamos

National Laboratory requests that the publisher ldentity this article as work performed under the auspices of the U.S. Department of Energy. 


\section{DISCLAIMER}

Portions of this document may be illegible in electronic image products. Images are produced from the best available original document. 


\section{DISCLAIMER}

This report was prepared as an account of work sponsored by an agency of the United States Government. Neither the United States Government nor any agency thereof, nor any of their employees, makes any warranty, express or implied, or assumes any legal liability or responsibility for the accuracy, completeness, or usefulness of any information, apparatus, product, or process disclosed, or represents that its use would not infringe privately owned rights. Reference herein to any specific commercial product, process, or service by trade name, trademark, manufacturer, or otherwise does not necessarily constitute or imply its endorsement, recommendation, or favoring by the United States Government or any agency thereof. The views and opinions of authors expressed herein do not necessarily state or reflect those of the United States Government or any agency thereof. 


\title{
Ultrasensitive Ultrasonic Transducer Studies
}

\author{
Raymond Dixon*, Timothy Darling, and Albert Migliori
}

\begin{abstract}
This is the final report of a one-year, Laboratory-Directed Research and Development (LDRD) project at the Los Alamos National Laboratory (LANL). This project sought to continue development of the ultrasensititve ultrasonic transducers that won a 1994 R\&D 100 Award. These transducers have a very smooth response across a broad frequency range and thus are extremely wellsuited for resonant ultrasound spectroscopy as well as pulsed-echo and acoustic-emission applications. Current work on these transducers has indicated that bonding the piezoelectric and wear surface to a metal foil and attaching the foil to a body is less expensive and produces a transducer that is as good or better than commercially produced transducers. We have diffusionbonded piezoelectric crystals and backings to stainless-steel-foil and wear surfaces. These are then attached onto stainless-steel tubes with electrical connectors to form the transducers. The transducers have been characterized using a reciprocity technique, electrical response, and optical interferometry. After characterization, the transducers have been compared to existing transducers by measuring and testing identical properties.
\end{abstract}

\section{Background and Research Objectives}

Ultrasonic transducers for use in industry and science need to be produced in a variety of sizes and designs in order to optimize the signals, minimize the effect on the object being measured, and deal with odd-shaped objects, limited access, and different environments. This continuous requirement to build new transducers for different projects led to construction techniques employing metallized plastic films and epoxy joints. Advantages of this design are: (1) ease and rapidity of fabrication, (2) the plastic decouples the transducer acoustically, and (3) with good choice of transducer and backload, a unit can be made that has little or no internal resonances in the frequency range of interest. Disadvantages of this design are: (1) often the electrical connections are capacitive because of the insulating properties of the epoxy layers, (2) "soft" epoxy and plastic layers between piezoelectric disc and backload degrade performance

*Principal investigator, e-mail: rd_dixon@lanl.gov 
by permitting unwanted modes of vibration in the transducer unit, and (3) the epoxy cannot withstand high temperatures and small-area bonds are weak. Strength can be improved, as in many commercial transducers, by "potting" the whole assembly in some damping material, such as epoxy, which also reduces the effect of any internal resonances. Unfortunately, this also has the effect of reducing the response of the transducer. The second disadvantage is of particular concern for doing non-destructive testing (NDT) and basic materials science because unwanted peaks from modes of the transducer can reduce the sensitivity of the transducer and interfere with the desired measurement. If the piezoelectric disc is held rigidly to a stiff, flat backload, its flexural modes (usually much lower frequency than the nominal firstcompressional or shear mode of the active element) are raised to frequencies near those of the bare backload. However, a layer of relatively soft epoxy and plastic will not provide strong enough coupling to shift these modes, so they may appear as unwanted peaks in the spectrum of an object. The major problem is the epoxy - it is non-conductive, plastic, degrades with time, and cannot handle harsh environments.

Our goal in this project was to refine the construction techniques for these transducers to be able to produce tough, highly sensitive transducers reliably, and to produce the measurement apparatus to test and demonstrate the properties.

\section{Importance to LANL's Science and Technology Base and National R\&D Needs}

This project supports Los Alamos core competencies in nuclear and advanced materials as well as complex experimentation and measurement. It has produced highly sensitive transducers that are rugged and reliable and that can be used in non-destructive testing techniques, basic materials science applications, and industrial applications.

\section{Scientific Approach and Results to Date}

Resonant Ultrasound Spectroscopy (RUS) [1] has applications in both basic science and industrial NDT. The transducers are presently a limiting factor of the usefulness of this technique, due to the fact that organic components of transducers cannot be used at high temperatures and have poor durability and short lifetimes. New durable, sensitive transducers will enable important advances to be made in both science and industrial applications using ultrasound. A solution to this problem, developed at Los Alamos, was considered significant enough to be awarded one of R\&D Magazine's R\&D 100 Awards in 1994. These transducers are also the subject of a patent application [2]. 
In essence, our solution replaces all of the epoxy joints with metal bonds. When two clean metal surfaces (i.e., free of oxides and other contaminants) are brought into contact under pressure and the temperature is raised above some threshold (dependent on the metal), metal atoms will diffuse across the contact boundary removing the surface-contact interface and effectively bonding the two metal parts into one part. The components of a transducer unit can be coated with metal, either electrochemically or by vacuum evaporation, and the resulting metal surfaces may be diffusion-bonded together, forming a conductive, strong, and durable bond, which is thinner than any glue and plastic joint. This thin and rigid bond is capable of adequately coupling the rigid backload (such as diamond) to raise the lowest mode to one consistent with the theoretical composite object, making such transducers as free as possible of unwanted low modes of the active element. This bonding technique is used in a few special industrial applications (e.g., titanium turbine blades). The conditions of surface cleanliness, and the pressures and temperatures, mean it is difficult to apply, and indeed just the temperatures needed to mobilize atoms in most metals would exceed the Curie temperature of the common piezoelectric ceramic materials (PZT-5, $\mathrm{T}_{\mathrm{C}}-350^{\circ} \mathrm{C}$ ) destroying piezoelectricity. The "noble" metals (copper, gold, and silver) with melting points near $1000^{\circ} \mathrm{C}$ can be bonded with acceptable values for pressure and temperature, provided the surface cleanliness condition can be met. Copper oxidizes readily and special conditions (vacuum, inert atmosphere) must be applied to maintain clean metal surfaces. Gold is inert and is suitable for bonds, but the temperature needed is at the high end of our allowed scale, around $300^{\circ} \mathrm{C}$. Silver has the unusual property that at $150^{\circ} \mathrm{C}$ the metal will dissolve its own oxide layer into the bulk, providing a clean surface. Bonding can thus be carried out in air. This, coupled with the fact that bonding can occur near $200^{\circ} \mathrm{C}$, made silver our primary choice for a bonding material, although we have also developed the capability for bonding other metals.

Initial experiments with silver-diffusion bonding were carried out at LANL [3] by bonding PZT-5 ceramic piezoelectrics to alumina backloads in air with electrochemically deposited films. Experiments were carried out to determine the optimal bonding pressure and time to make a good bond with various sizes of transducer. For a "safe" temperature of $200^{\circ} \mathrm{C}$ or slightly above, and a bonding time of 20 minutes, the bonding pressure to produce good bonds varied from $15,000 \mathrm{psi}$ for the largest transducers ( $1 / 2$ inch diameter) to $22,500 \mathrm{psi}$ for the smallest (1/16 inch diameter). Several transducers were successfully fabricated along the design of Figure 1 and showed excellent response. All bonds could be made simultaneously and the transducer casing and support were easily made mechanically robust. These transducers certainly cover the range useful for most NDT applications where parts are usually relatively large and thus have low resonance frequencies. There are no components in these units that are subject to deterioration with time. They will function in environments where 
solvents are present, and direct DC electrical connections are made, reducing low-frequency noise pickup. For basic materials science and for NDT of smaller components, we also produced small transducer units that are effective up to about $500^{\circ} \mathrm{C}$. This range is a considerable advance on the present capabilities. To develop these transducers further, we have constructed an ultra high-vacuum system to evaporate metal films and make the bonds. The vacuum is held at $10^{-6}$ Torr or better during this process so, at worst, only a few atomic layers of oxide could form. The thin $(0.004 \mathrm{inch}) \mathrm{LiNbO}_{3}$ discs we use are quite fragile so we use considerably less pressure than that used with the ceramic discs; but because the Curie point is higher, we use a higher temperature to increase the diffusion. Using silver films of $2,000 \AA$ to $5,000 \AA$ thickness, bonding at $250^{\circ} \mathrm{C}$ for 20 minutes, and applying a pressure of approximately $2,000 \mathrm{psi}$ we can reproducibly make a transducer unit comparable in size to our research units, but with superior properties. Two of the small transducers have been used in a high temperature RUS apparatus to measure the elastic properties of steel up to $500{ }^{\circ} \mathrm{C}$. The behavior of the peak frequencies is shown in Figure 2.

Measurements made on the electrical response of metal-diffusion-bonded and a commercial-damped transducer verify the idea of removing unwanted low frequency modes from the bonded unit. Figure 3 shows scans for (a) a commercially available transducer and (b) a diffusion-bonded PZT/Alumina transducer of similar size and type of piezoelectric, in the range $0.3 \mathrm{MHz}$ to $6 \mathrm{MHz}$. An apparatus for making measurements based on a reciprocity technique [4] has been assembled.

\section{References}

1. A. Migliori, J.L. Sarrao, William M.Visscher, T.M. Bell, Ming Lei, Z. Fisk and R.G. Leisure, "Resonant Ultrasound Spectroscopic Techniques for Measurement of the Elastic Moduli of Solids," Physica B 183, 1-24 (1993).

2. DOE Patent Disclosure, Case \#S-78,340.

3. Raymond D. Dixon and Albert Migliori, "Fabrication and Performance of Ultrasensitive Ultrasonic Transducers," Rev. Sci. Inst., submitted, LA-UR -95-1476 (1995).

4. G.W. Swift, A. Migliori, S.L. Garrett and J.C. Wheatley, "Two Methods for Absolute Calibration of Dynamic Pressure Transducers," Rev. Sci. Inst. 53, 1906-1910 (1982). 


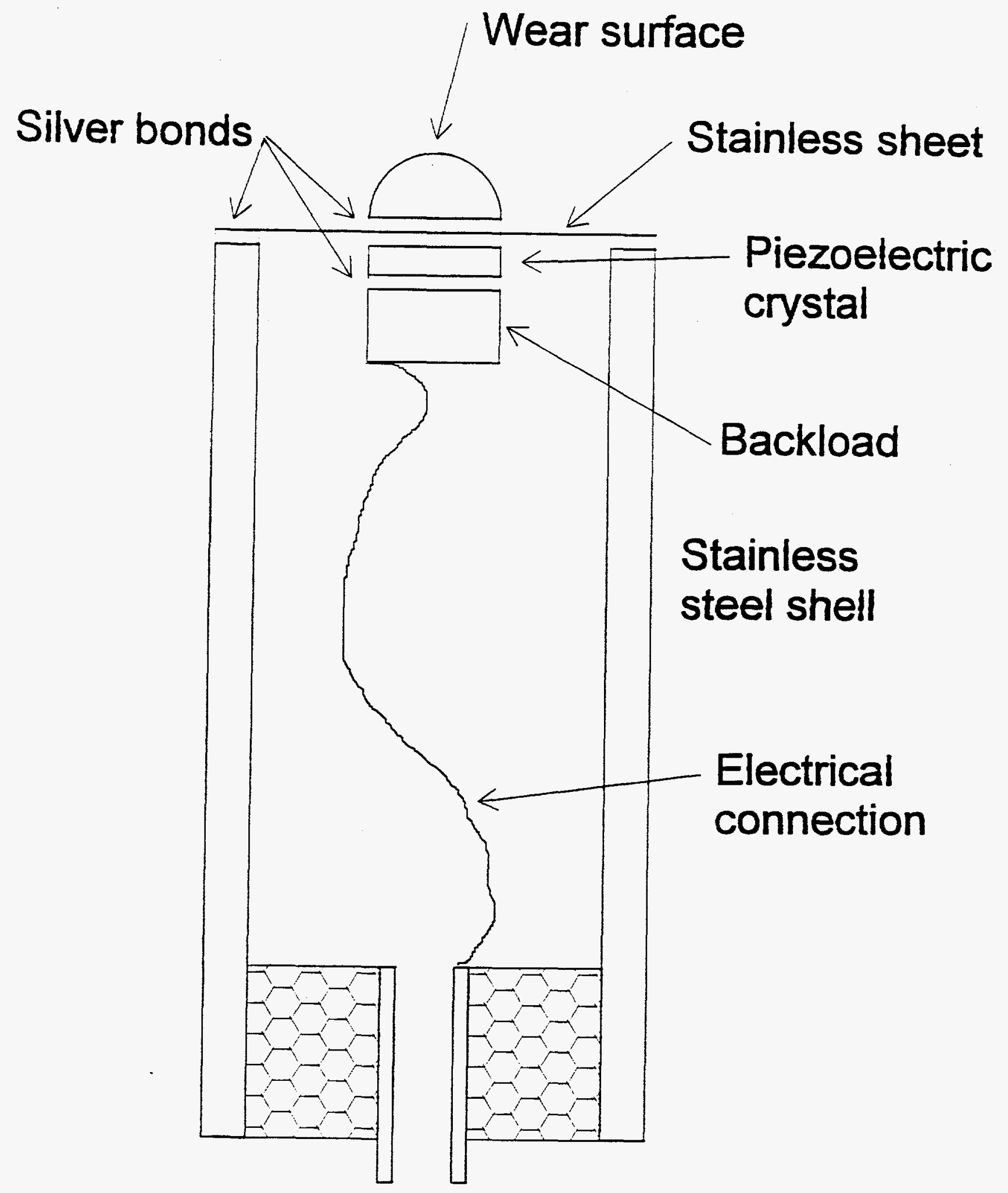

Figure 1. Construction of a stainless steel silver diffusion bonded transducer. 


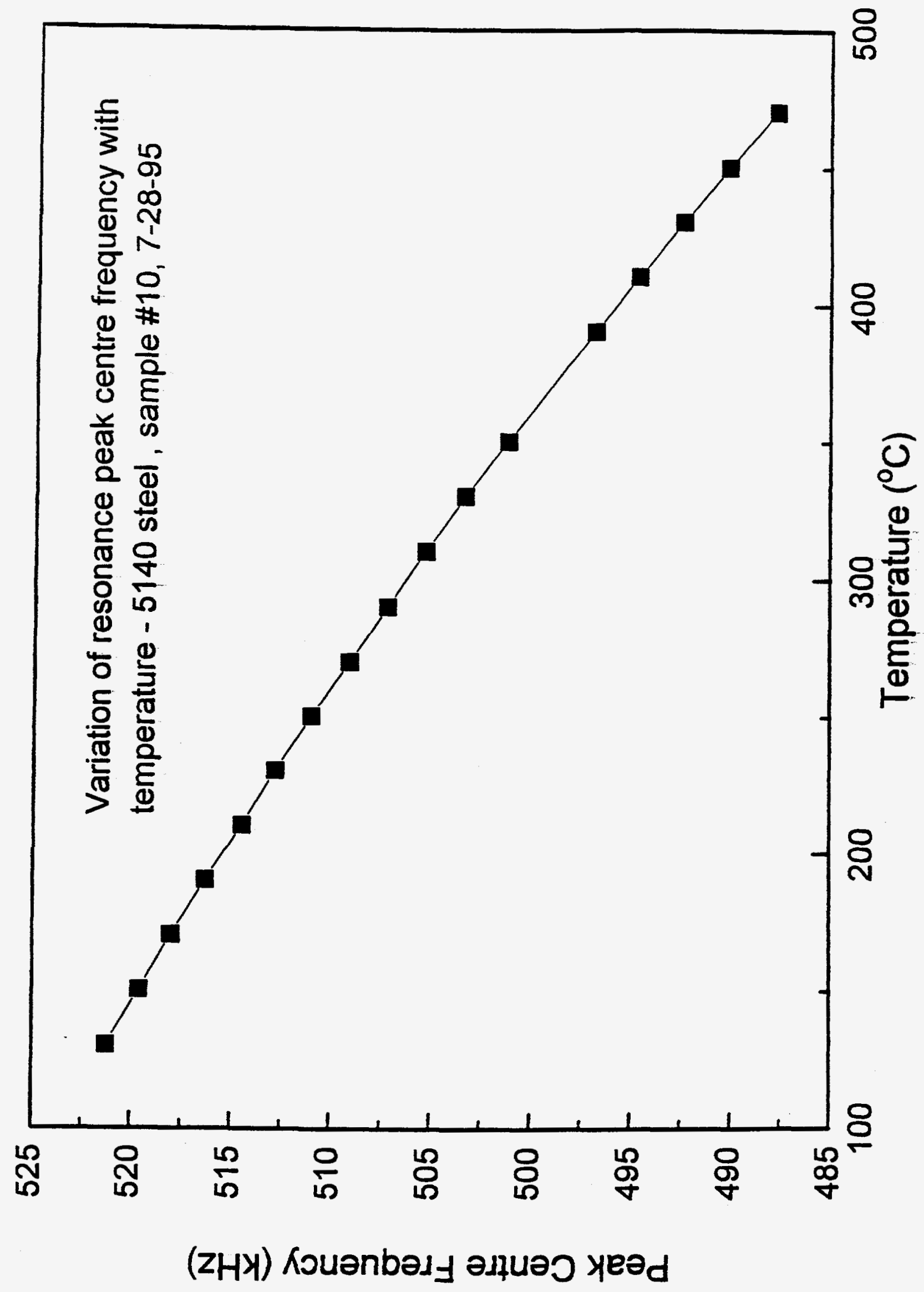

Figure 2. Measurements made up to $500^{\circ} \mathrm{C}$ with diffusion bonded transducers. 


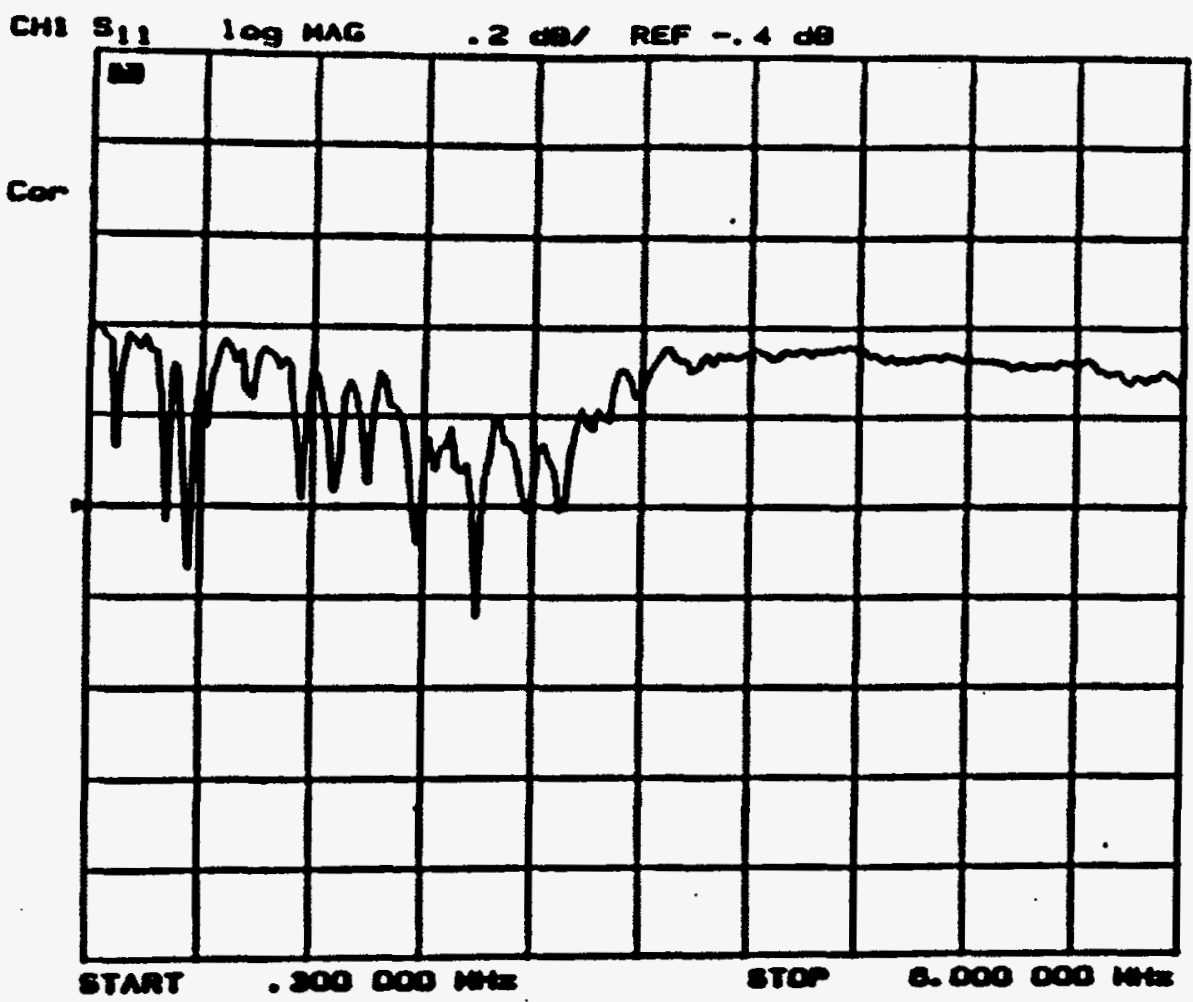

(a)

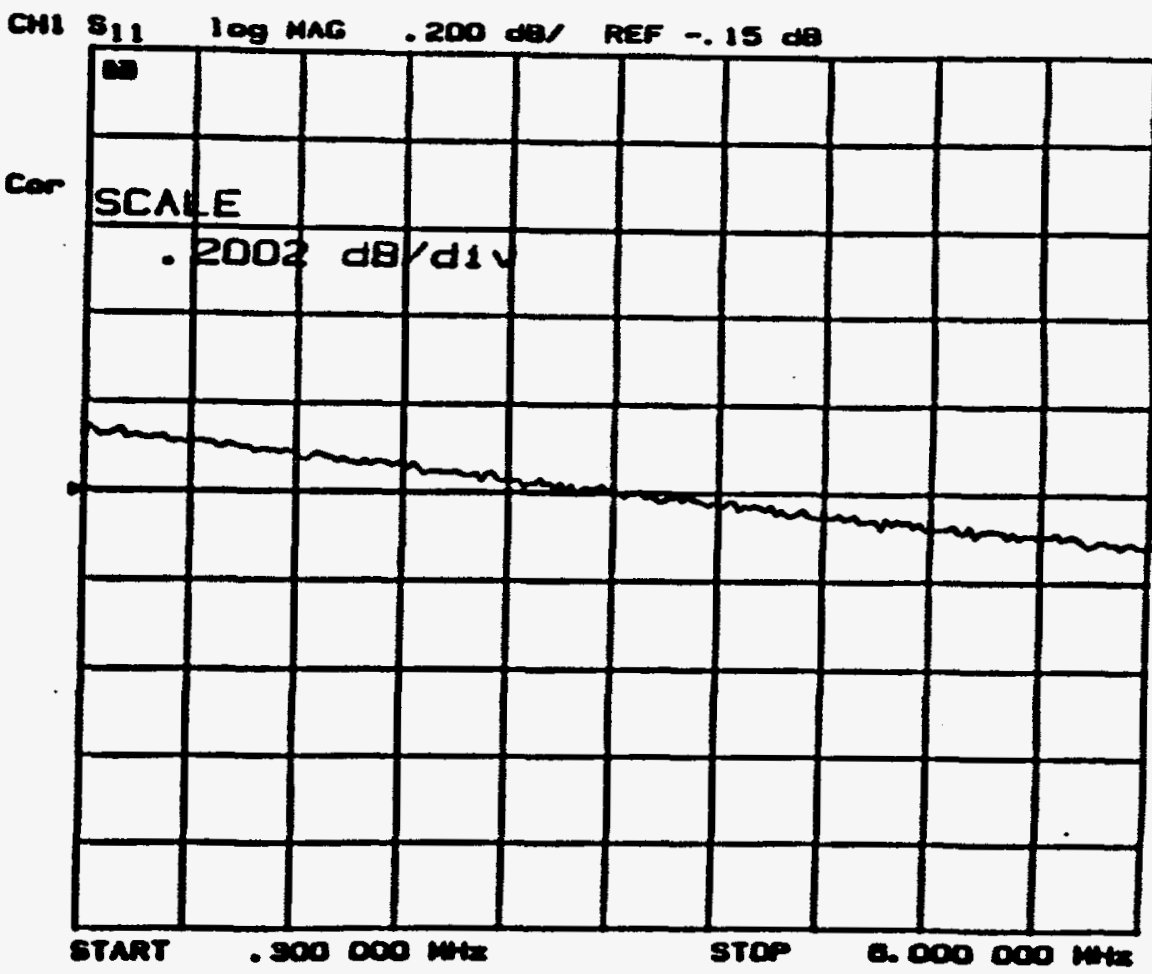

(b)

Figure 3. Comparison of the electrical response of (a) a commercial transducer and (b) a metal-bonded transducer. 